\title{
Shaping the System - The DRG Evaluation Project of the German Society for Gynaecology and Obstetrics (Deutsche Gesellschaft für Gynäkologie und Geburtshilfe, DGGG)
}

\author{
Das System gestalten - das DRG-Evaluationsprojekt der Deutschen Gesellschaft für Gynäkologie und Geburtshilfe \\ (DGGG)
}

Authors

Affiliations
W. Fiori ${ }^{1 *}$, S. P. Renner ${ }^{2 *}$, K. Siam ${ }^{1}$, J. Babapirali ${ }^{1}$, N. Roeder ${ }^{1}$, E. Dausch ${ }^{3}$, T. Hildebrandt ${ }^{2}$, P. Hillemanns ${ }^{4}$, M. Nehmzow ${ }^{5}$, M. Zygmunt ${ }^{5}$, D. Piroth ${ }^{6}$, C. Schem ${ }^{7}$, T. Schwenzer ${ }^{8}$, K. Friese ${ }^{9}$, D. Wallwiener ${ }^{10 * *}$, M. W. Beckmann ${ }^{2 * *}$

The affiliations are listed at the end of the article.

Key words
DRG
quality assurance
coding
DGGG
MDC
adaptation
Schlüsselwörter
DRG
Qualitätssicherung
Kodierung
DGGG
MDC
Adaptation

received 18.6.2013

revised 11.7.2013

accepted 18.7.2013

Bibliography

DOI http://dx.doi.org/

10.1055/s-0033-1350748

Geburtsh Frauenheilk 2013; 73 :

776-782 @ Georg Thieme

Verlag KG Stuttgart · New York .

ISSN 0016-5751

\section{Correspondence}

Dr. med. Wolfgang Fiori

DRG-Research-Group

Medizincontrolling

Geschäftsbereich Medizinisches Management

Universitätsklinikum Münster

Domagkstraße 20

48129 Münster

wolfgang.fiori@ukmuenster.de

http://drg.uni-muenster.de

\section{Abstract \\ $\nabla$}

Introduction: The German DRG system is annually adapted to the changing services provided. For the further development, the self-governing body and its DRG Institute (InEK) depend on participation of the users.

Methods: For one of the DRG evaluation projects initiated by DGGG, cost and performance data for the year 2011 from 16 hospitals were available. After plausibility checks and corrections, analyses for service and cost homogeneity were performed. In cases of inadequate DRG-representation attributes were sought that would make an appropriate reimbursement possible. Conspicuities and potential solutions were checked for clinical plausibility.

Results: 44 concrete modification proposals for further development of the G-DRG system were formulated and submitted in due time to the InEK. In addition, 3 modification proposals were addressed to the German Institute for Medical Documentation and Information (Deutsches Institut für Medizinische Dokumentation und Information, DIMDI) for further development of the diagnosis classification ICD-10-GM. For all modification proposals care was taken to minimise misdirected incentives and to reduce the potential for disputes with the cost bearers and their auditors services in settlements.

Discussion: The publication of the G-DRG system 2014 shows which modification proposals have been realised. Essentially, an appropriate redistribution of the resources among the gynaecological and obstetrics departments is to be expected. The financial pressure that is caused by the generally inadequate financing of hospitals will not be reduced by a further development of the G-DRG system.

\section{Zusammenfassung \\ $\nabla$}

Das G-DRG-System wird jährlich an die sich veränderte Leistungserbringung angepasst. Bei der Weiterentwicklung sind die Selbstverwaltungspartner und ihr DRG-Institut (InEK) auf die Beteiligung der Anwender angewiesen.

Methodik: Für ein von der DGGG initiiertes DRGEvaluationsprojekt wurden Kosten- und Leistungsdaten von 16 Kliniken aus dem Jahr 2011 bereitgestellt. Nach Plausibilisierungen und Korrekturen erfolgten Analysen zur Leistungs- und Kostenhomogenität. Wo Abbildungsschwächen bestanden, wurden Attribute gesucht, die eine sachgerechtere Vergütung ermöglichen könnten. Auffälligkeiten und Lösungsansätze wurden klinisch plausibilisiert.

Ergebnisse: 44 konkrete Anpassungsvorschläge für die Weiterentwicklung des G-DRG-Systems wurden erstellt und fristgerecht beim InEK eingereicht. Ergänzend wurden 3 Anpassungsvorschläge an das Deutsche Institut für Medizinische Dokumentation und Information (DIMDI) zur Weiterentwicklung der Diagnoseklassifikation ICD-10-GM gestellt. Bei allen Anpassungsvorschlägen wurde darauf geachtet, Fehlanreize zu minimieren und Streitpotenzial mit den Kostenträgern und ihren Prüfdiensten bei der Abrechnung zu reduzieren.

Diskussion: Welche Anpassungsvorschläge umgesetzt werden, zeigt sich mit der Veröffentlichung des G-DRG-Systems 2014. Im Wesentlichen wird eine sachgerechtere Umverteilung der Ressourcen zwischen den gynäkologischen und geburtshilflichen Kliniken zu erwarten sein. Der finanzielle Druck, der durch eine unzureichende Finanzierung der Krankenhäuser im Allgemeinen entsteht, kann durch eine Weiterentwicklung des G-DRG-Systems nicht reduziert werden.

* Joint authorship: both authors contributed equally in the preparation of this article.
** Joint authorship: both authors contributed equally in the preparation of this article. 


\section{Introduction}

\section{$\nabla$}

As of 2004 a large portion of the provided inpatient hospital services must obligatorily be accounted for via the DRG fixed relative weights. Since the introduction of the first G-DRG system in 2003 the G-DRG system, the settlement rules (FPV), the German coding standards (DKR) and underlying basic classification systems for diagnoses (ICD-10-GM) and procedures (OPS) have been annually developed further. In parallel the basis for calculation the data upon which the yearly further developments of the G-DRG system are based - has been continuously improved. The resultant G-DRG system has only little similarity with the originally copied Australian model and is now a world leader with regard to its differentiating ability and the thus realised fair and just distribution [1]. The development of the G-DRG system lies in the hands of the Institute for Reimbursement Systems in Hospitals (Institut für das Entgeltsystem im Krankenhaus, InEK), an organ of the self-governing partner in health-care services. On the other hand, the classification systems ICD-10-GM and OPS are cared for by the German Institute of Medical Documentation and Information (Deutsches Institut für Medizinische Dokumentation und Information, DIMDI). The DIMDI is an agency under the auspices of the Ministry of Health. Both seek and use the expertise of the users in the development process by a so called "structured dialogue" $[2,3]$. Without participation of the users the possibilities for further development of the reimbursement system in Germany would be limited. Because of the increasing complexity of the G-DRG system, however, it will be increasingly difficult for the professional medical societies to develop concrete modification proposals in the framework of the structured dialogue without external help. The still very high implementation rate of one third of the modification proposals for the G-DRG system on the other hand emphasises the relevance and necessity of the "structured dialogue" $[1,4,5]$.

In 2012 the German Society for Gynaecology and Obstetrics (Deutsche Gesellschaft für Gynäkologie und Geburtshilfe, DGGG) decided in cooperation with the DRG Research Group in Münster to initiate a DRG evaluation project. The aim of the project was to develop on the basis of a comprehensive analysis targeted modification proposals to improve the representation of the specialty in the G-DRG system and to incorporate them in the "structured dialogue".

\section{Method}

\section{$\nabla$}

In February 2012 and July 2012 a total of 440 hospitals with gynaecological department were approached twice by post concerning support of the project. 18 hospitals agreed to support the project financially, of these a couple were not allowed by their management to supply data. Altogether the cost and performance data of 16 hospitals for the year 2011 ( Table 1) were collected and evaluated. Besides five university hospitals a further 11 hospitals supplied data. The cost and performance data corresponded to the data that were supplied to the InEK [6]. Two further hospitals ( $\bullet$ Table 2 ) could only supply performance data because they did not supply information for the InEK calculation procedures and thus did not have any cost data available.
Table 1 Hospitals that were able to supply cost and performance data for the DRG evaluation project.

\begin{tabular}{l} 
Hospital \\
Pius Hospital Oldenburg \\
University Hospital Erlangen \\
Medical University Hannover \\
University Hospital Schleswig-Holstein Campus Kiel \\
Clinic St. Georg gGmbH Leipzig \\
DRK Hospital Chemnitz-Rabenstein \\
University of Regensburg Caritas Hospital St. Josef \\
Marien Hospital Herne \\
Clinic Coburg gGmbH \\
\hline Regional Hospital Starnberg GmbH \\
Clinic Oldenburg gGmbH \\
Marien Hospital Bottrop gGmbH \\
Westpfalz Clinic GmbH Kaiserslautern \\
\hline Hospital St. Joseph Stiftung Dresden \\
University Hospital Tübingen \\
Municipal Hospital Brandenburg GmbH
\end{tabular}

Table 2 Hospitals that were only able to supply performance data for the DRG evaluation project.

\section{Hospital \\ University Hospital Greifswald \\ University Hospital Aachen}

\section{Data Plausibility Checks \\ $\nabla$}

Coding errors or locally widely varying coding practices or expertise style among the controlling services of the cost-bearers (e.g., MDK) lead to variations in DRG assignments. On analysis of the DRG representations, deviations in DRG assignments could suggest not valid cost differences or smooth out existing cost differences. Accordingly, data transfer was followed by a comprehensive check of plausibility of coding with the help of over 300 for the specific specialty choosen validation rules. Emphasis was placed hereby on billing-relevant attributes (principal diagnosis, special additional diagnoses, OPS codes or, respectively, their combinations). In addition, plausibility checks were applied to attributes that do not yet have any relevance for grouping in the G-DRG system or as an additional reimbursement but which, however, are assigned a high potential for future relevance. Thus, for example, on the basis of the admission date and the procedure date for delivery, a comparison was made with the coded OPS code of the class 9-280 (stationary treatment prior to delivery in the same admission session). In cooperation with the hospitals, numerous coding errors could be corrected and the coding unified. Finally, only a very low number of cases $(<0.5 \%)$ - especially due to conspicuities in the cost data - had to be excluded from the further evaluation.

Ultimately, 52285 completely inpatient treatment cases (excluding the newly born babies and cases with services from private doctors or midwives) from 16 hospitals were available for an analysis of cost homogeneity of the G-DRG. Since cost and performance data of the DRG systems exist only for inpatient cases, no conclusions on outpatient reimbursement structures were possible from this project. The cases originating from the year 2011 were grouped into the systematics of the G-DRG system 2013 with the help of a so-called transition grouper. Thus it was 
possible to compare these costs with the cost values of the G-DRG cost calculation by the InEK. The 52285 cases were distributed among a total of $416 \mathrm{G}-\mathrm{DRGs}$. However, the emphasis of the evaluation was directed to G-DRGs of the 3 major diagnostic categories (MDCs) of relevance for the specialty:

- 09: Diseases and disorders of the skin, subcutaneous tissue and breast

-13: Diseases and disorders of the female reproductive system

14: Pregnancy, childbirth and the puerperium

For special analyses additional specific DGRs of the following MDCs were also taken into consideration:

- 06: Diseases and disorders of the digestive system $(\rightarrow$ e.g., endometriosis, adhesiolyses)

- 11: Diseases and disorders of the kidney and urinary tract $(\rightarrow$ incontinence surgery)

- 21B: Injuries, poisoning and toxic effects of drugs ( $\rightarrow$ e.g., breast surgery, prophylactic operations)

The case numbers available for analyses of the relevant individual DRGs included to an appreciable extent the data that were available to the InEK for calculation of the G-DRG system 2013. Thus, the proportion of inliers (duration of stay between the lower and upper trim points for a specific G-DRG) of the project in the InEK calculation sample in the for the specialty exclusive MDC14 (Pregnancy, childbirth and the puerperium) for example, amounted to between 10.6\% (G-DRG O63Z) and 52.8\% (G-DRG O02A). For childbirth DRGs it was a minimum of $22.4 \%$ for uncomplicated vaginal delivery (G-DRG O60D). With increasing complexity of the needed services the case proportion in the InEK calculation sample also increased. Thus there was a sufficiently large number of cases available for in-depth analyses with a slight over-representation of services from maximum and specialist care-givers.

For the analysis - besides the inlier cases that areexclusively used in the development of the G-DRG system - the so-called outliers were also taken into consideration. Low outliers (length of stay less than the lower trim point for a specific G-DRG) play an important role in gynaecology and obstetrics. Accordingly, in some relevant G-DRGs of the specialty, the great majority of the cases have lengths of stay below the lower trim point (for example, G-DRGs N09B "other interventions on vagina, cervix and vulva”, N10Z "diagnostic curettage, hysteroscopy, sterilisation, pertubation", $040 Z$ "abortion with dilatation und curettage, aspiration curettage or hysterectomy" or O63Z "abortion without dilatation and curettage, aspiration curettage or hysterotomy"). Patients with a longer duration of stay are also highly relevant. High outliers (patients with a length of stay longer than the upper trim point of a specific G-DRG) are, in order to create incentives, deliberately and systematically under-financed. However, if a longer duration of stay is systematically associated with a justifiable special and necessary service (for example, prevention of premature birth), this is not a sign for inefficient processes. Hospitals providing these services, however, may be penalised in spite of an economic provision of health care. Accordingly, particular attention was directed to such case collectives. Cases transferred to and from hospitals which may also be assigned as outliers do not quantitatively play a significant role. Only in those cases of postpartum maternal care (mainly transfers with a newborn requiring treatment), do appreciable case numbers arise that were analysed in detail.
In the analysis, apart from the duration of hospital stay, above all the costs were taken into consideration. After adjustment of the costs for expenses covered by additional reimbursements, the total costs were divided into so-called costs for the key service and the remaining differential costs that are regarded sensible to the duration of stay for further in-depth analysis. Costs for the key service and differential costs are constructs that are relevant for the development of the G-DRG system and for determining the increases and reductions for outliers [7]. By division of the differential costs by the duration of stay (differential costs/days in hospital) a "daily cost rate" could be determined. When required a break-down and consideration according to personnel costs, expenditures on material, and infrastructure costs or even an assessment at the level of individual fields of the InEK cost matrix was performed. In addition, revenues in the G-DRG system can be simulated. For this the German state-wide base rate 2013 (3068.37€) was used. However, costs from the year 2011 cannot be methodologically related to revenues of the year 2013 without reservations. Even so only this analysis offers the opportunity under consideration of the limitations - to estimate the extent of underfinancing for the high outliers.

For the identification of conspicuities in the performance of services, which may possibly require an altered or separate representation in the G-DRG system, a comparison was made not only with the case collective of the InEK but also an inter-hospital comparison was undertaken. The comparison with the case collective of the InEK served mainly to analyse the representation of the entire specialty. If this showed that the project collective exhibited a higher cost value or longer duration of stay than that in the InEK collective, the respective reasons were sought. On the one hand this could be due to the composition (e.g., relative specialisation) of the project sample or to an inappropriate condensation of services of different medical specialties at the level of the individual G-DRG. The comparison with the InEK collective is, however, always limited by the fact that, with the exception of the outlier quota, as yet only the calculation data for the inliers have been published. Only with the so-called implicated oneday-stay DRGs is it possible to derive the total costs in the InEK calculation sample from the value relation of the current G-DRG catalogue. Thus, a supplementary comparison of the total cost for short duration patients by means of the implicated one-day-stay DRGs was possible. The inter-hospital comparison, i.e., the juxtaposition of the values from the individual project clinics would make possible the identification of special characteristics in the services provided within the peer group. In part in direct communication with the project clinics it was attempted to extract the necessities for a system adaptation from the unspecific heterogeneity of the services provided.

By means of an analysis of clinical profiles [8] attributes (especially ICD and OPS codes) were sought that could serve as appropriate representations of the services. Thereby the average cost values of cases possessing the respective attribute were compared with the costs and the duration of hospital stay for the entire group. The entire group was considered to be the inliers/all cases of a G-DRG but also higher aggregations (for example adjacent DRGs).

In addition, the existing DRG split criteria, DRG condensations and individual DRG definition tables were checked for their appropriateness. Because of the broad spread of many clinical case collectives in gynaecology and obstetrics over various G-DRGs, DRG-overlapping evaluations and simulations had to be per- 
formed frequently. Supplementary analyses were undertaken on the basis of concrete leads from a DGGG working group.

On the basis of the described methodology, numerous adaptation options have been identified. Apart from classical changes of DRG definitions, these are also concerned with more complex reconstructions in the G-DRG system. In addition, numerous hints were found as to where changes/supplements to the coding standards and classification systems (ICD-10-GM und OPS) could contribute to a more appropriate representation. The adaptation options derived from the data analysis were then presented to the DGGG working group and discussed in detail. This was to ensure that the found conspicuities were not based on artefacts and that differences in expenditure could be understood from the clinical point of view. Furthermore, consultations were held on the incentives for a modified representation of the services in the G-DRG system. The aim was to submit only those adaptation proposals that could sustainably lead to a better representation of the services and to set as few false incentives as possible. Apart from false incentives for case selection and service control, the effects with regard to medically not needed documentation and the potential for conflict in the framework of the auditing process by the cost bearer were taken into consideration. In particular the mentioned aspects were taken into account when there was a choice of solutions to a constellation of problems. Solution options associated with an expected high expenditure of administrative effort were given low priorities.

Thus, care was taken to present solution options that could reduce false incentives. What does this mean? The delivery of a premature baby often has a better reimbursement than a birth after the 38th week of pregnancy. Because of the shorter prepartum hospitalisation, the costs for the inpatient stay are lower. The legal prerequisites and minimum patient numbers for a perinatal centre have not yet been taken into account in these considerations. The ethical professional view must stand above any financial pressure as the supreme good and so it is never justifiable in such situations to initiate delivery earlier than is necessary for purely financial gain.

Altogether very little time was available in that year's DRG development cycle for the analysis, discussion and formulation of modification proposals. Although the InEK presented the preliminary version of the G-DRG system 2013 at the end of August 2012 to the self-governing bodies as planned, agreement at the level of the self-governing bodies again proved to be difficult. Even so and in contrast to the previous year when the Ministry of Health had to carry out a substitute performance, an agreement on the G-DRG system was achieved. On 19.10.2012 - approximately 4 weeks later than in the years before - the systematics of the new G-DRG system were published and the software for transfer of the data from the year 2011 into the G-DRG system 2013 was certified [9]. On 28.11.2012 the final version of the G-DRG system 2013, which also took the ICD and OPS codes valid for 2013 into account was published. This version was especially important for the analysis of the MDC 09 data because considerable changes in the OPS coding of senological interventions were made between 2011 and 2013. On 19.12.2012 the final report of the InEK and the report browser 2011/2013 with the cost and performance data of the InEK calculation sample, which was necessary for the differentiated evaluation, was published [1].
Table 3 Summary of the submitted modification proposals.

\begin{tabular}{|c|c|}
\hline \multicolumn{2}{|l|}{ DIMDI } \\
\hline - Modification proposals to ICD-10-GM & 3 \\
\hline - Application for FAQ entry & 1 \\
\hline \multicolumn{2}{|l|}{ InEK } \\
\hline - Modification proposals to the coding standards & 4 \\
\hline $\begin{array}{l}\text { Modification proposals to MDC } 09 \\
\text { (Diseases and disorders of the skin, subcutaneous tissue } \\
\text { and breast) }\end{array}$ & 9 \\
\hline $\begin{array}{l}\text { Modification proposals to MDC } 11 \\
\text { (Diseases and disorders of the kidney and urinary tract) }\end{array}$ & 1 \\
\hline $\begin{array}{l}\text { Modification proposals to MDC } 13 \\
\text { (Diseases and disorders of the female reproductive system) }\end{array}$ & 6 \\
\hline $\begin{array}{l}\text { Modification proposals to MDC } 14 \\
\text { (Pregnancy, childbirth and the puerperium) }\end{array}$ & 24 \\
\hline
\end{tabular}

\section{Results}

$\nabla$

Modification proposals had to be submitted to the DIMDI in suitable form by at the latest 28.02.2013 and those to the InEK by 31.03.2013 at the latest. A number of in part very complex modification proposals as well as adaptation options containing numerous partial proposals was selected and submitted on time by the DGGG ( Table 3 ). The respective documents are available on request from the authors.

The modification proposals for the further development of ICD10-GM concerned, among others:

- The establishment of specific ICD codes for infections or other complications due to breast prostheses or implants. The current coding by way of organ unspecific ICD codes leads in connection with DKR $1205 \mathrm{~d}$ to the grouping of the cases in the (unspecific) collection DRGs of MDC 21B ("Injuries, poisoning and toxic effects of drugs"), which does not represent the performance adequately (specifically).

- The establishment of specific ICD codes for the care of the mother in case of (suspected) malformation of the cardiovascular system or, respectively, the respiratory organs of the foetus. Here also it is seen that an adequate representation including contingency costs for complicated cases is not achieved with the current (unspecific) codes.

- The establishment of a specific ICD code for the tubular breast and clarification of the coding with regard to Poland's syndrome.

The application for an FAQ entry addresses the coding of plastic reconstruction in connection with a myoma enucleation. The representation in the OPS catalogue and in the G-DRG system at first appears to be adequate. However, in many places - possibly on the basis of the undifferentiated coding recommendation No. 382 of the social medicine expert group (SEG) 4 of the MDK dated 12.04.2011 (www.mdk.de/1534.htm) - an adequate coding and DRG representation is not realised. At issue here - and this is shown by individual discussions with the MDK - is to what extent a reconstruction of the uterus is part ("procedure component") of the OPS code for myoma enucleation. The working group of the DGGG is of the opinion that there are indeed myoma enucleations for which an extensive reconstruction of the uterus (e.g., large myomas with a wide intramural extension) is not a part ("procedure component") of the OPS code for myoma enucleation. Other myoma enucleations for which no reconstruction is required (subserous myomas with only a small myometral de- 
fect, for which among others, merely an adaptation or coagulation is needed) are adequately represented by the corresponding OPS code.

The modification proposals for further development of the coding standards concern among others:

- Clarification and lifting of the contradictions in the choice of principal diagnosis in obstetrics (DKR 1505a, 1506f, 1511a, 1512d and 1519e) [10]

- Acceptance of the multiple classification with ICD codes for the organ chapter in obstetrics (DKR 1510b)

- Clarification in the choice of principal diagnosis for infections or other complications for breast prostheses or implants (DKR 1205d), additional/corresponding modification options to the DIMDI (see above)

- Establishment of a new DKR for the choice of principal diagnosis for prophylactic operations (e.g., women with BRCA 1/BRCA 2 mutations) and deletion of the paragraph in DKR 1205d concerning subcutaneous prophylactic breast amputation

The modification proposals to MDC 09 concern among others:

- Representation of a combination of multiple interventions on the breast and female sexual organs in MDC 09

- Representation of breast reduction surgery (currently G-DRG J06Z, J24B)

- Separation of senological cases from the dermatology-dominated adjacent DRG J11

- Representation of plastic reconstruction with pedicled skinmuscle grafts (myocutaneous flaps), with/without prosthesis implantation (currently G-DRG J14B, J24B)

- Representation of bilateral prosthesis implantations (currently G-DRG J16Z) and annulment of the condensation with radiotherapy cases,

- Representation of the various mastectomy procedures (currently adjacent DRG J24)

- Representation of the implantation of a skin expander (currently G-DRGs J23Z, J16Z, J06Z and J24B)

- Procedure split of G-DRG J25Z or, respectively, case shift of special procedure combinations in the adjacent DRG J07

Analyses and modification proposals for MDC 09 have been made difficult by the fact that between 2011 and 2013 the procedure coding in senology was fundamentally changed. The coding for the data year 2011 could thus not be automatically transferred to the systematics of the OPS catalogue 2013.

The modification proposals for MDC 11 address the representation of paraurethral injection treatment with Bulkamid (currently G-DRG L17B). Altogether it was seen that ambiguities in the coding of the principal diagnosis frequently occurred within the framework of incontinence treatment. It should be mentioned that, according to DKR D002f, when a pathology is specifically treated the pathology itself and not the symptomatics is to be coded as the principal diagnosis. The disputed coding recommendation No. 57 of the SEG 4 of the MDK, which contradicts DKR D002f and leads to an inappropriate DRG grouping, should not be employed for coding in gynaecology and obstetrics. Many cases with a colporrhaphy and other operations are assigned on the basis of a wrong choice of the principal diagnosis to the G-DRGs of MDC 11 which are under-reimbursed for this service. With a correct coding an appropriate representation - mostly in G-DRG N06Z - would be achieved.

The modification proposals for MDC 13 concern among others:

- Assignment of all manifestations of endometriosis to MDC 13
- Complex restructuring of the unspecific adjacent DRG N11 that collects cases that cannot be assigned to more specific DRGs to avoid underpayment of additional services (numerous other G-DRGs of MDC 13 affected)

- Representation of cases with the principal diagnosis of a malignancy and avoidance of underpayment for additional services (numerous other G-DRGs of MDC 13 affected)

- Representation of "simple" hysterectomies in connection with lymphadenectomies (currently adjacent DRG N03)

- Decondensation of interventions on the uterus and adnexa in cases with malignancy on other organs as well as reconstructions of vagina and vulva (currently G-DRG N03A)

- Representation of the various forms of ureterolysis

The modification proposals for MDC 14 concern among others:

- Financing of longer prepartum hospital stays to avoid a premature birth (currently adjacent DRGs 001, 002 and 060)

- Condensation of the adjacent DRGs for vaginal delivery (002 and 060) and establishment of a new split construct

- Representation of instrumented vaginal deliveries (currently adjacent DRGs 002 and 060)

- Elimination of the "error-DRG" $962 Z$ and annulation of DKR $1506 f$

- Representation of special complicating diagnoses and procedures in connection with delivery in numerous individual proposals (e.g., coagulopathies, complications, uterus extirpations)

- Complex restructuring of prepartum admissions and pregnancies with abortive outcomes (currently adjacent DRGs 003, 005, 006, 040, 062, 063, 064 and 065)

- Consideration of special complicating diagnoses (e.g., infections, mental disorders) in prepartum admissions (currently adjacent DRG 065)

- Diagnoses split for G-DRG O61Z to separate cases with complications and co-hospitalisation due a new-born baby requiring treatment in postpartum admissions

Furthermore, an expert opinion about the problems in the regulation of maternity hospitalisation according to §24 f SGB V or $\S 197$ RVO instead of $\S 39$ SGB V (hospitals treatment) was formulated. Because of these deviating regulations, the use of many other provisions that are based on $\S 39$ SGB V is made difficult. This concerns, for example, the rules for the six-week period and administration fee in the auditing process by the health insurances (§ 275 para. 1c SGB V).

\section{Discussion}

$\nabla$

To what extent the submitted modification proposals will be realised in the sense of the DGGG remains to be seen. Already due to their sheer number and complexity it is doubtful that a comprehensive analysis and processing by the InEK will be possible within one adaptation cycle. Ultimately, it remains open, even with sufficient time, whether or not problems and solution proposals - identified on the basis of the not always representative project data from the year 2011 - can be reproduced also for the calculation collective of the InEK in the G-DRG system 2014 (costs and performance data for 2012). By plausibility verification of the data-driven, achieved hypotheses with the help of the working group of the DGGG, this does, however, seem possible for most of the modification proposals. Even so it must be 
considered that many of the modification options may interact mutually and that the processing (prioritisation) of the submitted modification proposals may have an impact on the probability of their realisation. In addition, other users and institutions may also submit modification proposals. Furthermore, general system changes such as, for example, an adaptation of the degree of severity matrix for additional diagnoses (so-called CCL matrix) or the hierarchic arrangement of the DRG requests in the algorithm can have a considerable impact on the composition of the affected G-DRGs (especially in MDC 13). Last but not least, modification proposals can, in spite of apparent false representations and consequent solution proposals, fail when no agreement on a solution can be achieved among the self-governing bodies. This practically always affects modification proposals on coding guidelines and on the establishment of additional payments that do not refer to services that have already received interim financing as new examination and treatment methods (NUB). Nevertheless, modification proposals to the above-mentioned problems can still be meaningful. After the self-governing bodies had obliged the user and especially the professional societies to cooperate by means of the "structured dialogue" in the further development of the G-DRG systems it was demonstrated that representation problems could be identified and constructive solutions sought. The responsibility for weak representations and inappropriate distributions then goes back to the self-governing bodies. The professional societies can then strongly and with high legitimation demand a solution for representation problems [11]. On the whole, it must be considered that within the framework of the DRG evaluation project it is only possible to highlight solution options that impact on the fair and just distribution of resources. Mostly an improved representation of the services in the G-DRG system leads "only" to a redistribution within a peer group. This means that there is on the one side a "winner" but on the other side there will also be a "loser" within the specialty group. On the basis of the strictly data-based adaptation of the G-DRG system, however, the "loser" had ultimately always been the (unjust) "winner" of a previously undifferentiated representation. Due to the adaptation the "winner" merely receives that portion of the cake to which he/she is entitled in a fair and just allocation [12].

\section{Outlook}

$\nabla$

The G-DRG-system is mainly used as an instrument to set incentives for an economic performance of services and to distribute the limited financial resources as appropriately as possible among the service providers. Although the financial pressure that nowadays burdens all hospitals is frequently ascribed to the G-DRG system, this will become less and less due to the G-DRG system with the increasing equitable distribution of resources [13]. Increasingly serious are the lack of refinancing of the increasing costs in the hospitals and the reduced investments by the states. In contrast to the equitable distribution, the underlying questions that concern the (solidary) financing of hospital services can only be solved at the political level.

Nevertheless hospitals are forced to respond to the increasing financial pressure. It is thus advisable to have knowledge of one's own position in the competitive market. Accordingly, the hospitals participating in the DRG evaluation project received a comprehensive benchmarking report that allows a comparison of the services provided at the DRG level with the project group and with German nation-wide comparative data. Now that, due to the complexity of the G-DRG system, the specialty-specific services are scattered over numerous different G-DRGs, a benchmarking report at the level of the clinical services groups was provided $[14,15]$. With this report the provision of services can be compared on the basis of more or less predictable or, respectively, strategic development of accessible clinical case collectives. The comparison on the basis of clinical service groups offers the possibility to identify the strengths and weaknesses of one's own hospital and to deduce specific needs for action or development potentials.

The new G-DRG system 2014 will probably be available for analysis at the end of 2013. As soon as the grouper software becomes available, quantitative estimations will be possible as to what effects the further development will have for the specialty and its subspecialties. The authors will then report on the relevant changes.

\section{Acknowledgements \\ $\nabla$}

This project was made possible by the financial support of the following hospitals (towns/cities in alphabetical order). Some of the hospitals were not allowed by their administrations to supply data to the project:

- University Hospital Aachen, Aachen

- Municipal Hospital Brandenburg GmbH, Brandenburg

- DRK Hospital Chemnitz-Rabenstein, Chemnitz

- Clinic Coburg gGmbH, Coburg

- Hospital St. Joseph-Stiftung Dresden, Dresden

- University Hospital Erlangen, Erlangen

- University Hospital Greifswald, Greifswald

- Medical Hospital Hanover, Hanover

- Ruprecht-Karls-University Heidelberg, Universitätsklinik, Heidelberg

- Marien Hospital Herne, Herne

- University Hospital Schleswig-Holstein Campus Kiel, Kiel

- Clinic St. Georg gGmbH, Leipzig

- Clinic the University of Munich, Campus Innenstadt, München

- Dietrich-Bonhoeffer Clinic Neubrandenburg, Neubrandenburg

- Clinic Oldenburg gGmbH, Oldenburg

- University of Regensburg, Caritas Hospital St. Josef, Regensburg

- University Gynaecological Clinic Tübingen, Tübingen

- University Hospital Ulm, Ulm

\section{Conflict of Interest}

\section{$\nabla$}

The members of the DRG Research Group conduct trainings, work as consultants and render expert opinions for a multitude of different stakeholders, interest groups and companies in the health care sector.

\footnotetext{
Affiliations

${ }^{1}$ Medizincontrolling, Geschäftsbereich Medizinisches Management, Universitätsklinikum Münster, DRG-Research-Group, Münster

${ }^{2}$ Universitätsklinikum Erlangen, Frauenklinik, Erlangen

${ }^{3}$ Klinik für Frauenheilkunde und Geburtshilfe an der Unversität Regensburg,

Caritas-Krankenhaus St. Josef, Regensburg

${ }^{4}$ Medizinische Hochschule Hannover, Frauenklinik, Hannover

${ }^{5}$ Universitätsklinikum Greifswald, Frauenklinik, Greifswald

${ }^{6}$ Universitätsklinikum Aachen, Frauenklinik, Aachen

${ }^{7}$ Universitätsklinikum Kiel, Frauenklinik, Kiel

8 Frauenklinik, Klinikum Dortmund Mitte, Dortmund

${ }^{9}$ Universitätsklinikum München, LMU, Frauenklinik, München

10 Universitätsklinikum Tübingen, Frauenklinik, Tübingen
} 


\section{References}

1 Institut für das Entgeltsystem im Krankenhaus GmbH (InEK GmbH). Abschlussbericht „Weiterentwicklung des G-DRG-Systems für das Jahr 2013“, Klassifikation, Katalog und Bewertungsrelationen, Teil I: Projektbericht, Siegburg, 19. Dezember 2012. http://www.g-drg.de/cms/ G-DRG-System_2013/Abschlussbericht_zur_Weiterentwicklung des_G-DRG-Systems_und_Report_Browser; last access: 01.06.2013

2 Institut für das Entgeltsystem im Krankenhaus GmbH (InEK GmbH). Vorschlagsverfahren zur Einbindung des medizinischen, wissenschaftlichen und weiteren Sachverstandes bei der Weiterentwicklung des G-DRG-Systems (G-DRG Vorschlagsverfahren). http://www.g-drg.de/ cms/G-DRG-Vorschlagsverfahren; last access: 01.06.2013

3 Deutsches Institut für Medizinische Dokumentation und Information (DIMDI). Vorschlagsverfahren zur Pflege von OPS und ICD-10-GM für Zwecke des G-DRG-Systems. http://www.dimdi.de/static/de/klassi/ icd-10-gm/vorschlagsverfahren/index.htm; last access: 01.06.2013

4 Lux MP, Fasching PA, Loehberg CR et al. Health services research and health economy - quality care training in gynaecology, with focus on gynaecological oncology. Geburtsh Frauenheilk 2011; 71: 1046-1055

5 Beckmann MW, Bader W, Bechtold I et al. Finanzierung und finanzielle Probleme von Leistungen und Strukturen im Fachgebiet Gynäkologie und Geburtshilfe im Jahr 2011 - DRG-System und stationäre Versorgung inklusive Urogynäkologie und benigner wie auch maligner gynäkologischer Operationen. Geburtsh Frauenheilk 2011; 71: 497-510

6 Anlage zur Vereinbarung über die Übermittlung von Daten nach § 21 Abs. 4 und Abs. 5 KHEntgG: Daten nach § 21 KHEntgG - Version 2012 für das Datenjahr 2011, Fortschreibung vom 1. Dezember 2011. http://www.g-drg.de/cms/content/download/4162/33679/version/3/ file/V-21-KHEntgG_A-2012_2011-12-01.pdf; last access: 01.06.2013
7 Institut für das Entgeltsystem im Krankenhaus GmbH (InEK GmbH). Abschlussbericht „Weiterentwicklung des G-DRG-Systems für das Jahr 2005“, Klassifikation, Katalog und Bewertungsrelationen, Teil I: Projektbericht, Siegburg, 20. Dezember 2004. http://www.g-drg.de/cms/ content/download/1046/6861/version/2/file/Abschlussbericht_ G-DRG-2005_0412201200.pdf; last access: 01.06.2013

8 Roeder N, Bunzemeier H, Loskamp N et al. DRG-Transparenz durch klinische Profile. Das Krankenhaus 2003; 4: 289-292

9 Institut für das Entgeltsystem im Krankenhaus GmbH (InEK GmbH). Dokumente zum G-DRG-System 2013. http://www.g-drg.de/cms/ G-DRG-System_2013; last access: 01.06.2013

10 Fiori W, Engels-Lozowski M, Kiesel L et al. Kodierung in der Geburtshilfe. So schwierig wie eine Einkommensteuererklärung? Frauenarzt 2003; 44: $124-133$

11 Kolberg H-C, Lüftner D Lux MP et al. Breast cancer 2012 - new aspects. Geburtsh Frauenheilk 2012; 72: 602-615

12 Fasching PA, Ekici AB, Adamietz BR et al. Breast cancer risk - genes, environment and clinics. Geburtsh Frauenheilk 2011; 71: 1056-1066

13 Fiori W, Bunzemeier H, Roeder N. Warum das Geld nicht reicht. Nicht an allem sind die DRGs schuld. Das Krankenhaus 2012; 10: 989-995

14 Helling J, Bunzemeier H, Fiori W et al. Klinische Leistungsgruppen - Update und Ausblick. Das Krankenhaus 2009; 9: 857-862

15 Roeder N, Siebers L, Frie M et al. DRG-Akzeptanz verbessern. Kliniker erreichen mit klinischen Leistungsgruppen. Das Krankenhaus 2006; 5: 390-401

Deutschsprachige Zusatzinformationen online abrufbar unter: www.thieme-connect.de/ejournals/toc/gebfra. 